\title{
Author Correction: Defective Sphingosine-1-phosphate metabolism is a druggable target in Huntington's disease
}

\author{
Alba Di Pardo ${ }^{1}$, Enrico Amico ${ }^{1}$, Abdul Basit $\mathbb{1}^{2}$, Andrea Armirotti ${ }^{2}$, Piyush Joshi ${ }^{3}$, M. Diana \\ Neely ${ }^{3}$, Romina Vuono ${ }^{4}$, Salvatore Castaldo ${ }^{1}$, Anna F. Digilio ${ }^{5}$, Francesco Scalabri ${ }^{1}$, Giuseppe \\ Pepe $^{1}$, Francesca Elifani ${ }^{1}$, Michele Madonna ${ }^{1}$, Se Kyoo Jeong ${ }^{6}$, Bu-Mahn Park ${ }^{7}$, Maurizio \\ $D^{\prime} E_{s p o s i t o}^{1,8}$, Aaron B. Bowman ${ }^{3}$, Roger A. Barker ${ }^{4}$ Vittorio Maglione ${ }^{1}$
}

Correction to: Scientific Reports https://doi.org/10.1038/s41598-017-05709-y, published online 13 July 2017

The original version of this Article contained a typographical error in the spelling of the author M. Diana Neely, which was incorrectly given as Diana M. Neely. This has now been corrected in the PDF and HTML versions of the Article as well as the Supplementary Information that now accompanies the Article.

(i) Open Access This article is licensed under a Creative Commons Attribution 4.0 International cc. License, which permits use, sharing, adaptation, distribution and reproduction in any medium or format, as long as you give appropriate credit to the original author(s) and the source, provide a link to the Creative Commons license, and indicate if changes were made. The images or other third party material in this article are included in the article's Creative Commons license, unless indicated otherwise in a credit line to the material. If material is not included in the article's Creative Commons license and your intended use is not permitted by statutory regulation or exceeds the permitted use, you will need to obtain permission directly from the copyright holder. To view a copy of this license, visit http://creativecommons.org/licenses/by/4.0/.

(c) The Author(s) 2018

\footnotetext{
${ }^{1}$ IRCCS Neuromed, Pozzilli, Italy. ${ }^{2}$ Department of Drug Discovery and Development, Fondazione Istituto Italiano di Tecnologia, Genova, Italy. ${ }^{3}$ Departments of Pediatrics, Neurology and Biochemistry, Vanderbilt University (VU) and VU Medical Center Pediatric Neurology Research Lab, Nashville, TN, USA. ${ }^{4}$ John van Geest Cambridge Centre for Brain Repair, Department of Clinical Neuroscience, University of Cambridge, Cambridge, UK. ${ }^{5}$ Institute of Biosciences and Bioresources (IBBR), National Research Council (CNR), Naples, Italy. ${ }^{6}$ Department of of Cosmetic Science, Seowon University, Cheongju, Korea. ${ }^{7}$ NeoPharm USA Inc. Engelwood Cliffs, New Jersey, USA. ${ }^{8}$ Institute of Genetics and Biophysics "A. Buzzati-Traverso", Naples, Italy. Correspondence and requests for materials should be addressed to V.M. (email: vittorio.maglione@neuromed.it)
} 